\title{
Fundamentos conceituais para uma teoria do planejamento urbano baseada em decisões
}

\author{
Conceptual foundations for a decision-based theory of urban planning
}

Renato T. de Saboya

Doutor em Cadastro Técnico Multifinalitário e Gestão Territorial pela Universidade Federal de Santa Catarina (UFSC), professor dos cursos de Graduação e de Pós-Graduação em Arquitetura e Urbanismo da UFSC, Florianópolis, SC - Brasil, e-mail: rtsaboya@gmail.com

\section{Resumo}

Apesar de as decisões serem essenciais ao planejamento, esse conceito não tem recebido a devida atenção na literatura, especialmente se considerarmos os avanços obtidos em outros campos do conhecimento, com especial destaque para as abordagens do apoio à decisão construtivista e da psicologia comportamental. Este artigo faz um breve apanhado de alguns desses avanços e, a partir deles, explora as repercussões de sua incorporação e reenquadramento em uma teoria do planejamento urbano. Para isso, inicialmente define o conceito de decisão adotado e propõe uma classificação das decisões em três tipos: executivas, substantivas e processuais. Em seguida, explora quatro aspectos essenciais do planejamento cujo entendimento pode ser aprofundado sob a ótica da decisão: a) a construção de convicção sobre o problema; b) o caráter dinâmico da formulação do problema; c) a dificuldade e a necessidade de estimar desdobramentos futuros; d) as relações entre meios, fins e os conflitos de interesses envolvidos; e e) a necessidade de abrangência e exaustividade. Por fim, esses aspectos são utilizados como base para a identificação de fragilidades nos atuais esforços de elaboração de planos de desenvolvimento urbano e de oportunidades de aperfeiçoamento na direção processos mais justos, democráticos e eficazes.

Palavras-chave: Teoria do planejamento urbano. Teoria da decisão. Cognição. Planos urbanos.

Participação popular.

\section{Abstract}

Despite the fact that planning is inexorably based on decisions, this concept has not gathered the attention it deserves in urban planning literature, especially when we consider the latest achievements in the fields of constructivist decision aiding and behavioral psychology. This paper briefly reviews these achievements and explores the consequences of their integration into the framework of urban planning theory. In order to do this, it initially elaborates a working definition and proposes a threefold classification of decisions: executive, substantive and procedural. Then, explores four key aspects of planning that can be more deeply understood 
from the viewpoint of decision-making and decision-aiding: a) conviction building; $b$ ) the evolving nature of problem formulation; $c$ ) the difficulties and the need to estimate future developments; $d$ ) the relationship between means, ends and the ensuing conflicts of interests; and e) the need for comprehensiveness. Finally, these aspects are used as a basis for the recognition of weaknesses in current urban development initiatives and the identification of opportunities for improvement aimed at making these processes fairer, more democratic and effective.

Keywords: Planning theory. Decision theory. Cognition. Urban plans. Participatory planning

Quando um homem acrescenta uma contribuição, tem maior probabilidade de cometer um erro a seu favor do que em seu detrimento; e, quando um homem raciocina, está mais apto a incorrer em falácias a favor de seus desejos do que de frustrá-los. Assim, no estudo dos pensadores abstratos são seus erros que dão a chave de sua personalidade.

(RUSSEL, 2008, p. 35)

\section{Introdução}

Decisões estão no cerne de todo processo de planejamento. Elas são tomadas a todo tempo, na definição de quais objetivos devem ser perseguidos ou priorizados e de quais ações são consideradas as mais efetivas para alcançar esses objetivos. Entretanto, esse papel central não encontra proporcional aprofundamento na literatura, especialmente se considerarmos os avanços na teoria da decisão realizados nas últimas décadas. Este trabalho é um primeiro passo na direção de diminuir a distância entre esses campos de investigação; para isso, esboçamos as bases conceituais fundamentais para uma teoria do planejamento centrada na decisão, apoiando-nos no referencial teórico da escola europeia de apoio à decisão construtivista (Constructivist Multicriteria Decision Aiding - MCDA-C) (BANA E COSTA, 1993; ENSSLIN; MONTIBELLER NETO; NORONHA, 2001; ROY, 1993, 1996) e nos estudos de cognição aplicados ao julgamento e aos processos decisórios (ARIELY, 2008; KAHNEMANN, 2011; SIMON, 1955, 1973, 1981; TVERSKY; KAHNEMANN, 1974).

O papel essencial da decisão na teoria do planejamento urbano pode ser observado em correntes de pensamento das mais diversas matizes, desde as abordagens mais tradicionais do planejamento racional até as mais recentes, incluindo o planejamento comunicativo (INNES, 1996) e o just-in-time (ALFASI; PORTUGALI, 2004). 0 planejamento sistêmico, por exemplo, descreve o processo de planejamento de maneira muito similar ao processo tradicional de decisão, com definição de objetivos, avaliação de alternativas e seleção da melhor alternativa, e defende explicitamente a realização de escolhas racionais através de critérios derivados dos objetivos definidos (McLOUGHLIN, 1969). Lindblom (1959) critica fortemente o planejamento racional argumentando que, na prática, é impossível haver consenso em relação a objetivos e, portanto, o consenso só seria possível com relação às alternativas. Não obstante, sua base conceitual para explicar o processo também fundamenta-se na decisão.

Davidoff e Reiner (1973, p. 11) definem planejamento como "um processo para determinar ações futuras através de uma sequência de escolhas", e ressaltam que sua definição de planejamento "enfatiza o exercício da escolha como seu principal ato intelectual" (DAVIDOFF; REINER, 1973, p. 18). Mais recentemente, Bryson (2004, p. 17) alega que "[o planejamento estratégico] é durável porque leva em consideração a inteligência política, a racionalidade e a tomada de decisões". No corpo de teorias do planejamento que ficou conhecido como "comunicativo", Innes (1996, p. 461) explora as condições para que decisões sejam "comunicativamente racionais" e defende o consenso como a forma de chegar a uma decisão: "Quando o grupo tiver explorado os interesses e concordado em relação aos fatos, eles criam opções, desenvolvem critérios para escolha e tomam decisões com as quais todos concordem".

Apesar de todas essas abordagens apoiarem-se fortemente no conceito de decisão, via de regra esse conceito não é adequadamente aprofundado, no sentido de incorporar e problematizar os achados 
mais recentes das ciências da decisão e recontextualizá-los para o conjunto de preocupações e dilemas próprios do planejamento urbano. Apesar de algumas exceções ${ }^{1}$, de forma geral a abordagem padrão costuma apresentar um salto entre o reconhecimento da importância dos processos decisórios e o subsequente estabelecimento, com viés fortemente normativo, de princípios e diretrizes sobre como esses processos deveriam ser conduzidos.

Neste trabalho, por outro lado, adotamos uma postura mais descritiva do que normativa ou prescritiva (BARON, 2008) e mais dedutiva do que hipotética, entendendo, entretanto, que uma explicação de aspectos-chave proporcionada por uma descrição bem feita pode contribuir para a promoção de processos melhores e mais adequados. Isso é especialmente importante se considerarmos o contexto atual do planejamento urbano no Brasil, no qual, por um lado, há um acúmulo precário de reflexão sobre teoria do planejamento em seus aspectos processuais e, por outro, há enormes desafios aos profissionais responsáveis pela condução e elaboração de planos de desenvolvimento urbano, desafios esses introduzidos em sua maior parte pela falta de treinamento específico em condução de processos participativos aliada à obrigatoriedade da ampliação da participação imposta pelo Estatuto da Cidade (Lei Federal n. 10.257/01).

Não surpreendentemente, não são raros os casos em que essa condução fica aquém do satisfatório. Santos Jr. e Montandon (2011, p. 28), por exemplo, em uma revisão de 526 Planos Diretores implementados após o Estatuto da Cidade, concluem: “[...] nem todos os Planos Diretores são efetivamente resultado de um pacto social para a gestão do território municipal [...]". Mais adiante, acrescentam:

Outro grave problema parece ter permeado o processo de elaboração dos Planos: a manutenção da cisão entre uma visão técnica da cidade e uma visão comunitária/popular. Em alguns estudos de caso, certos temas foram tratados bastante superficialmente ou não foram tratados (SANTOS Jr; MONTANDON, 2011, p. 277)².

Neste estudo, levamos em consideração apenas as decisões que possuem características especialmente relevantes ao contexto do planejamento urbano. Essa delimitação inclui decisões que:

- possuem consequências importantes para uma grande quantidade de pessoas;

- são enfrentadas e tomadas de forma consciente, ainda que nem todos os fatores que as influenciam estejam claros para os decisores; - são tomadas coletivamente.

Decisões de cunho essencialmente pessoal fogem aos propósitos deste trabalho; por esse motivo, usaremos sempre o termo decisores no plural para nos referirmos às pessoas responsáveis por tomar uma decisão relacionada ao planejamento urbano, sejam a Câmara de Vereadores, os técnicos de planejamento, a sociedade civil, o Conselho da Cidade ou qualquer outro ator, trabalhando em conjunto ou isoladamente.

0 artigo estrutura-se da seguinte forma: a primeira parte delineia alguns conceitos fundamentais e discute brevemente alguns avanços das teorias da decisão em suas vertentes construtivista de apoio à decisão e psicológica/comportamental. Em seguida, aprofunda algumas das consequências desses novos entendimentos para o processo de planejamento urbano, explorando seus rebatimentos e inter-relações. Por fim, destaca e comenta os principais avanços no entendimento do papel das decisões em planejamento urbano e levanta possíveis caminhos para o aprimoramento de processos de elaboração de planos urbanos.

\footnotetext{
1 O planejamento comunicativo, por exemplo, utiliza subsídios do conceito de racionalidade limitada de Simon (1955) (FORESTER, 1989). Outra abordagem que pode ser considerada uma exceção é o Decision-centred view of environmental planning, de Faludi (1987), que por sua vez baseia-se no Strategic Choice Approach (FRIEND; HICKLING, 2005).

2 Reveladora, também, é a grande quantidade de Planos Diretores cuja elaboração e/ou aprovação foram contestadas na justiça, dentre as quais podemos citar Salvador (BA), Itajaí (SC), Jaú (SP), São Sebastião (SP), Paraty (RJ), Guaíba (RS), São Luís (MA) e Brasília (DF). Para um estudo mais aprofundado da experiência de Florianópolis (SC), ver RABELLO, 2012.
} 


\section{Decisão, processo decisório e limites da racionalidade}

Decisão é entendida, neste trabalho, como um processo no qual, a partir da consideração e reflexão sobre uma determinada situação problemática, bem como as possíveis alternativas para sua resolução, uma conclusão é alcançada com relação a qual curso de ação deve ser seguido. Situação problemática ou situação decisional, por sua vez, referem-se a uma situação em que:

- há uma discrepância entre as condições previstas para o futuro e aquelas desejadas pelos decisores;

- não há uma alternativa que seja simultaneamente: a) de conhecimento dos decisores; b) claramente superior a todas as outras conhecidas pelos decisores; e c) considerada satisfatória pelos decisores;

- há, como consequência das duas condições anteriores, incertezas quanto a qual seria o curso de ação mais adequado a ser tomado.

\section{Teorias comportamentais e construtivistas da decisão}

Teorias comportamentais e construtivistas podem ser entendidas como duas abordagens distintas dentro do vasto campo de estudos relacionados à decisão. Entretanto, ambas nasceram de trabalhos que investigaram a capacidade do cérebro humano de armazenar, processar e utilizar informações (CLÍMACO, 2004) e, por isso, possuem muitos pontos em comum.

Dentre os estudos mais importantes e influentes no que diz respeito a processos de tomada de decisões estão os de Herbert Simon $(1955,1973)$. Em $A$ behavioral model of rational choice, Simon (1955) contrapõe à abordagem tradicional, originada dos estudos econômicos, uma abordagem mais descritiva e menos normativa, buscando entender como as decisões são tomadas em situações reais. Ele argumenta que limitações cognitivas dos decisores não podem ser negligenciadas, o que acaba contrariando a premissa do homem perfeitamente racional assumido pela economia, que teria conhecimento completo ou quase completo de todos os aspectos relevantes do problema, além de um sistema estável de preferências e capacidade computacional suficiente para analisar todas as alternativas em termos de utilidade com relação a esse sistema.

Para tomar uma decisão perfeitamente racional, uma pessoa deveria ser capaz de estimar com precisão os benefícios das várias alternativas consideradas, o que exige, por sua vez, a perfeita previsão de quais seriam as consequências de cada alternativa. Entretanto, esse processo de coleta e processamento de informações possui um custo e, por isso, há um momento do processo em que os decisores optam por interrompê-lo e executar a decisão, mesmo que não tenham esgotado todas as possibilidades. Portanto, a avaliação das consequências não é feita em termos de uma alternativa ótima ${ }^{3}$, mas em termos de satisfatório/insatisfatório, ou de ganhar/ perder/empatar.

Além disso, problemas complexos podem ser considerados mal-estruturados ${ }^{4}$, no sentido de que: a) não há critérios claros sobre os quais basear a avaliação de alternativas; b) não é possível delimitar, sem riscos de omissão, as variáveis a serem levadas em consideração e as alternativas possíveis; e c) o que é conhecido sobre o problema em um determinado momento do processo é muito diferente do que é possível de ser conhecido, isto é, há um componente processual que impõe condições muito diferentes aos decisores no início do processo e em seu fim (MINTZBERG; RAISINGHANI; THÉORÊT, 1976).

Esse é um entendimento fundamental para a escola construtivista de apoio à decisão, também conhecida como Escola Europeia de Apoio à Decisão. Segundo autores dessa linha de investigação (BANA E COSTA, 1993; EDEN; JONES, 1983; ENSSLIN; MONTIBELER NETO; NORONHA, 2001; ROY, 1996), o fato de que a definição do problema não é clara para os decisores no início do processo indica a necessidade de que ela seja construída

\footnotetext{
3 Entendida como a melhor alternativa possível segundo métodos matemáticos de otimização.

4 Ill structured, no original. Ver: SIMON, 1973
} 
paulatinamente. No começo, os decisores possuem apenas uma ideia fragmentada, confusa e incompleta sobre o problema, incluindo aí incertezas quanto a quais variáveis são essenciais e quais são secundárias, bem como quanto a seus próprios valores e objetivos, preferências, critérios, relações de dependência etc. Às vezes, a estruturação do problema pode mudar radicalmente após um esforço de entendê-lo e organizá-lo.

Isso, por sua vez, levou ao reconhecimento do papel central dos aspectos subjetivos na decisão (BANA E COSTA, 1993, p. 4):

Se é verdade que a procura da objectividade é uma preocupação importante, é crucial não esquecer que a tomada de decisão é antes de tudo uma actividade humana, sustentada na noção de valor, e que, portanto, a subjectividade está omnipresente e é o motor da decisão.

Portanto, as preferências dos decisores são tão importantes quanto os aspectos mais objetivos que caracterizam as alternativas. Entretanto, mesmo seus sistemas de preferências não são perfeitamente claros: eles podem mudar (e frequentemente mudam) com o desenvolvimento do processo.

Fragilidades dos processos cognitivos, como a instabilidade de preferências, são mais aprofundadamente estudadas pelas teorias comportamentais da decisão. Ariely (2008), por exemplo, mostrou que essa instabilidade pode alcançar níveis extremos nos quais uma simples diferença na combinação de alternativas é capaz de desestabilizar as preferências do decisor. Em um estudo de caso, Ariely (2008) demonstrou que a preferência pela alternativa $\mathrm{A}$ em relação à $\mathrm{B}$, ou vice-versa, poderia depender do fato de uma terceira alternativa $C$ constar ou não do conjunto de alternativas oferecidas a eles.

Outro fator cognitivo relevante para situações decisionais é a ancoragem, entendida como a tendência de utilizar a primeira alternativa oferecida em uma interação como base para a consideração sobre as demais opções, distorcendo os julgamentos na direção da alternativa inicial (ARIELY, 2008; FURNHAM; BOO, 2011; KAHNEMAN, 2011; TVERSKY; KAHNEMAN, 1974). Em uma situação de barganha posicional, a primeira sugestão carrega um poder de influência desproporcional à sua razoabilidade, apenas e tão somente pelo fato de ter sido a primeira a ser lançada, mesmo que tenha sido originada, por exemplo, por métodos aleatórios como o girar de uma roleta (TVERSKY; KAHNEMAN, 1974). Portanto, mesmo sugestões despropositadas, lançadas por participantes mal-intencionados, podem acabar sendo usadas como âncora em decisões importantes.

Por fim, destacamos o que Tversky e Kahneman (1974) chamam de disponibilidade, segundo o qual a probabilidade de um evento é estimada a partir da facilidade com que exemplos desse evento podem ser evocados pela memória: "Por exemplo, uma pessoa pode estimar o risco de um ataque cardíaco na meia-idade relembrando tais ocorrências entre pessoas que conhece" (TVERSKY; KAHNEMAN, 1974, p. 1127). Nossa capacidade de estimar probabilidades, portanto, é altamente influenciada por nossas experiências mais imediatas e, por isso, seriamente limitada quando essas experiências não são representativas de contextos mais amplos (o que sói acontecer, apesar de não ser necessariamente sempre o caso - vide observações mais adiante sobre o conhecimento local e comunitário).

\section{Planejamento urbano sob a luz dos estudos da decisão: uma tipologia básica das decisões em planejamento}

Inicialmente, propomos uma classificação das decisões relevantes para o planejamento urbano em três grandes tipos sem, entretanto, pretender esgotar as formas de decisões realizadas nesses processos. É importante observar também que essa diferenciação não deve ser entendida como algo absoluto; na realidade, esses níveis de decisão estão tão intimamente ligados que, muitas vezes, é impossível separar um de outro. Entretanto, os tipos propostos são úteis para fins analíticos, como instrumentos de reflexão que contribuem para a construção do modelo descritivo objeto deste trabalho.

0 primeiro tipo de decisão está, a rigor, fora do âmbito do planejamento propriamente dito, podendo mais precisamente ser atribuído ao campo da gestão urbana. Os outros dois estão no cerne do planejamento e podem ser chamados de decisões substantivas e decisões processuais. Esses conceitos serão tratados a seguir. 
Decisões de primeira ordem: decisões executivas

O primeiro nível de decisão, chamado aqui de executiva, é aquele que acontece quando um ator se compromete com um determinado curso de ação e empreende todos os recursos necessários para cumprir as subações imprescindíveis à sua efetivação. No âmbito do planejamento e da gestão urbanos, são as decisões que desencadeiam as ações que, de alguma forma, interferem diretamente no espaço da cidade e na sua dinâmica: a construção de um novo edifício, a compra de um terreno, a instalação de um novo comércio em um local específico, a construção de uma nova avenida, a implantação de uma linha de transporte coletivo, a emissão de uma licença para construção, a escolha de uma determinada rota para deslocar-se ao trabalho e assim por diante.

Assim como outros tipos de decisões, as do tipo executivo relacionam-se entre si, em níveis diferentes de generalidade e especificidade, segundo os quais algumas ações são desmembradas em subações. Uma decisão executiva de construir um edifício, por exemplo, requer a seleção de uma localização, a contratação de uma equipe de profissionais para elaborar o projeto, a requisição e o pagamento das licenças requeridas, a contratação de mão de obra, a limpeza do terreno etc. Cada uma dessas subações poderia ser desmembrada em ações ainda mais específicas.

São as decisões executivas que efetivamente produzem e reproduzem a cidade em toda a sua complexidade, abarcando decisões públicas e privadas que, com diferentes graus de coordenação entre os agentes e de granularidade em seus impactos, resultam nas ruas, edifícios, parques, padrões de circulação de pessoas e mercadorias, distribuição dos usos do solo, densidades populacionais, padrões de acessibilidade e valores do solo, bem como os demais aspectos relativos ao espaço urbano.

Essas ações podem ou não ter sido previamente planejadas; entretanto, a ideologia do planejamento sugere fortemente que essas decisões levem em consideração as decisões tomadas na fase de planejamento (entendidas como decisões de segunda ordem, como veremos adiante). Nesse sentido, um erro comum cometido pela teoria do planejamento é tratar decisões executivas simplesmente como ações, e não como decisões propriamente ditas; segundo essa visão, as decisões de planejamento (de segunda ordem) devem determinar inequivocamente quais ações devem ser tomadas no futuro e, portanto, uma decisão só é tomada naquele momento, cabendo às etapas seguintes apenas executar o que foi previamente decidido. Entretanto, essa visão negligencia a complexidade do processo, adotando uma postura mecanicista segundo a qual o que ficar decidido no plano deve ser cumprido, custe o que custar, sendo qualquer desvio considerado um distanciamento de uma situação ideal, supostamente cristalizada no plano.

Entretanto, o momento da execução de decisões concretizadas nos planos são, em si, momentos de decisão. Obviamente, elas podem (e devem) ser influenciadas pelas decisões anteriores, mas estão inevitavelmente sujeitas a uma série de fatores que podem induzir modificações no plano original, muitas vezes de forma significativa. Dentre esses fatores estão, por exemplo, o surgimento de novos fatos ou evidências não disponíveis anteriormente; os valores dos decisores, que podem atuar para filtrar seletivamente, dentre as prescrições do plano, aquelas ações mais alinhadas com seus próprios interesses; ambiguidades contidas nas prescrições, que deixam margem para diferentes interpretações; e pressões políticas e econômicas que movem grande quantidade de recursos e de relações de influência, muitas vezes de forma sub-reptícia e com amplos alcances temporais e espaciais.

Decisões de segunda ordem: decisões substantivas

O segundo nível de decisão envolve aquelas decisões que, com maior frequência, costumamos associar ao conceito de planejamento. São as decisões substantivas (ou de segunda ordem), isto é, aquelas que estabelecem o conteúdo do plano e definem os rumos desejados para o futuro, tanto em termos de meios (estratégias, programas, ações, normas reguladoras) como de fins (objetivos). Devemos construir uma nova avenida conectando dois bairros? A densidade populacional deveria ser alta ou baixa nessa área? Deveríamos impedir usos comerciais nessa zona? Elas devem servir de orientação, ao menos hipoteticamente, para as ações a serem tomadas no futuro. Mais precisamente, elas orientam as decisões futuras, que aqui são chamadas de decisões executivas ou de primeira ordem. 
0 termo orientam, nesse contexto, tem um sentido amplo. Ele abrange desde instruções muito detalhadas e específicas para a execução de uma ação, até princípios gerais que devem informar - mas não diretamente determinar - decisões futuras. Algumas dessas formas de orientação são programas, instrumentos reguladores, estabelecimento de prioridades e princípios gerais.

Decisões de terceira ordem: decisões processuais

0 terceiro nível de decisões diz respeito às condições sob as quais as decisões de segunda ordem serão tomadas e, portanto, está mais ligado aos aspectos processuais. Em processos complexos de tomadas de decisões coletivas, os aspectos processuais adquirem papel especialmente importante uma vez que a validade das decisões é, em larga medida, determinada por eles (FALUDI, 1973). Esse nível corresponde, portanto, ao fulcro do campo de estudos comumente chamado de teoria do planejamento urbano, mais especificamente ao conceito de theory of planning, em oposição ao de theory in planning (FALUDI, 1973) e possuem a atribuição de decidir como esse conteúdo será definido. Algumas decisões cruciais nesse nível são: como identificar (ou construir, dependendo do referencial teórico adotado) os objetivos dos decisores? Como priorizar esses objetivos? Como gerar comprometimento com um determinado curso de ação? Em que momento devem ser encerradas as discussões e iniciada a elaboração de pactos ou a votação dos pontos de conflito? Qual será a forma de decisão? Quem pode participar em cada etapa do processo, e em que condições? Como divulgar o processo e sensibilizar os participantes? Como estruturar as discussões para que sejam produtivas? Como garantir legitimidade às decisões?

\section{A construção de convicção sobre o problema}

Assim como Simon (1955, 1973), as teorias de apoio à decisão construtivista apoiam-se na rejeição da noção de decisores e processos decisórios perfeitamente racionais. Entretanto, elas utilizam o conceito de convicção (em substituição ao de satisfação) para lidar com o fato de que não é possível haver certeza absoluta sobre qual é a melhor alternativa em um contexto decisional complexo e, ainda assim, haver a necessidade de que uma decisão seja tomada. Convicção parece mais apropriado que o conceito de satisfação porque consegue explicar outros fatores necessários para a tomada de decisão além da simples consideração sobre a adequação de uma alternativa, tais como: a) o tempo necessário para amadurecer o entendimento do problema, especialmente sob o ponto de vista psicológico; e b) a satisfação com o leque de alternativas levantadas até o momento e suas prováveis consequências.

\section{Construção de conhecimento}

A principal estratégia utilizados pelos decisores para gerar convicção é construir conhecimento sobre o problema: conhecer os valores daqueles envolvidos e/ou afetados de alguma maneira pelas decisões, os condicionantes, a dinâmica urbana, as alternativas disponíveis e todos os outros aspectos considerados relevantes para o problema. Essa construção de conhecimento, entretanto, tem alto custo, não apenas financeiro, mas também de outras naturezas. 0 primeiro deles, e mais óbvio, é o tempo. As informações necessárias não estão imediatamente disponíveis e precisam ser coletadas, organizadas, interpretadas. Algumas vezes, precisam ser construídas caso a caso, como acontece com relação aos valores dos participantes. Eventos participativos precisam ser planejados cuidadosamente, divulgados, processados, disponibilizados e prorrogados ou estendidos caso necessário.

Um segundo tipo de custo se refere à capacidade de atenção dos decisores. Em um contexto de escassez de tempo e abundância de tarefas a serem realizadas, o tempo disponível para se dedicar a uma situação decisional relativa a um problema de planejamento urbano é, na grande maioria dos casos, extremamente reduzido. Representantes da sociedade civil precisam harmonizar horários de participação em eventos com sua rotina cotidiana, normalmente bastante atribulada. 0 mesmo acontece com relação aos representantes eleitos, tanto do executivo quanto do legislativo. Mesmo os técnicos responsáveis pela condução do processo de planejamento, em muitos casos, não podem se dedicar exclusivamente a essa tarefa. 
Por fim, um custo normalmente negligenciado pelas teorias do planejamento é o esforço necessário para compreender a situação decisional e o problema a ser resolvido, que impõe um custo cognitivo que não pode ser desprezado, pois possui repercussões importantes para o processo de planejamento. A etapa de estruturação do problema, vista anteriormente, é a que mais demanda esse tipo de esforço. A diversidade de visões sobre o problema impõe dificuldades para que os participantes consigam "enquadrá-lo" em uma estrutura ou modelo representacional satisfatório, o que exige não apenas atenção no sentido passivo do termo, mas também esforço intelectual considerável para lidar com incertezas e, ao mesmo tempo, entender o que é importante no problema, quais são as relações e influências mútuas entre os aspectos, como organizar seus pontos de vista para poder comunicá-los ao grupo, e assim por diante.

\section{Otempo como fator material e psicológico}

Conforme Simon (1955), se os decisores identificam muito rapidamente uma alternativa satisfatória, eles provavelmente prolongarão sua busca por alternativas e adotarão padrões mais altos de avaliação, em vez de se contentarem com as alternativas iniciais facilmente alcançadas. Isso acontece porque eles desejam ter confiança de que o conjunto de alternativas consideradas será o melhor possível dento de um dispêndio razoável de recursos (financeiros, humanos, de tempo, de esforço cognitivo etc.). Alternativas fáceis e rápidas normalmente não fornecem a convicção necessária para a solução de problemas decisionais complexos.

Portanto, a convicção não está relacionada apenas aos aspectos substantivos do problema, mas também, e principalmente, a aspectos psicológicos. Se não é possível haver certeza absoluta quanto a uma decisão, então, por consequência, acaba havendo um "salto" (uma espécie de leap of faith) em algum momento toda vez que uma decisão é tomada. Esse salto é, na verdade, uma estratégia para lidar com a complexidade.
Entretanto, há tensão entre a intensidade desse salto e os riscos inerentes a uma decisão mal feita. A importância dessa tensão não pode ser subestimada: ela impacta em situação decisionais, na maioria das vezes retardando o comprometimento com um curso de ação em busca de aumentar a convicção e suavizar os custos psicológicos envolvidos no processo. Além disso, o ato de selecionar e comprometer-se com uma alternativa envolve a desistência de adotar outras alternativas, juntamente com os possíveis benefícios que elas supostamente trariam e que não estão contemplados na alternativa selecionada. Em toda decisão há, portanto, custos não apenas relacionados à renúncia (concreta ou presumida) de aspectos substantivos, como também custos emocionais atrelados a essa renúncia.

\section{Consenso sobre previsões}

Outro fator que influencia a construção de convicção é a existência ou ausência de consenso sobre as previsões feitas com relação às possíveis consequências das alternativas (conforme discutido adiante) ou, dito de outra maneira, sobre: a) as teorias do funcionamento do sistema urbano implícitas ou explícitas no processo de discussão; e b) as supostas preferências daqueles afetados pelas decisões, mas que não podem expressar diretamente seus pontos de vista. Se há relativo consenso sobre esses fatores em relação a uma determinada decisão, é mais provável que a convicção apareça.

\section{Múltiplos pontos de vista}

Por outro lado, a oportunidade de ouvir opiniões conflitantes pode ser uma aliada importante à construção de convicção. A obtenção de consenso pode ser algo enganoso, pois nem sempre é fácil saber se é resultado de intensa e válida negociação e entendimento mútuo ou de suposições superficiais e negligência na consideração de consequências potencialmente problemáticas, que, por alguma razão, são mantidas sem discussão por influência de alguns participantes ${ }^{5}$. Nesses casos, as pessoas ten-

\footnotetext{
${ }^{5}$ Ver, por exemplo, Vainer (2002) e sua discussão sobre a imposição de consenso no planejamento estratégico.
} 
dem a permanecer em estado de desconfiança se percebem que os argumentos sobre um determinado assunto foram defendidos apenas por um grupo relativamente hegemônico de interesses específicos. Em outras palavras, se a inexistência de controvérsias, ora citada, é percebida como se devendo ao fato de que apenas um dos lados está presente e tem a chance de manifestar-se, isso gera um sentimento de desconfiança que prejudica a geração de convicção.

Por fim, uma observação importante sobre a construção de convicção: durante o processo decisório não é possível saber com certeza se ela foi atingida ou, em outras palavras, se o nível de convicção atingido em uma determinada decisão é suficiente para fazer o processo avançar, no sentido de dar por encerradas (ainda que provisoriamente) as discussões sobre o tema e comprometer-se com um curso de ação específico. Essa determinação sobre a suficiência ou não da conviç̧ão é, em si, uma decisão de terceira ordem (processual), e também deve ser submetida a acordos e consensos. Não é surpreendente, então, que isso abra a possibilidade de distorções no processo; frequentemente observamos atores com interesses ocultos atuando no sentido de apressar as decisões para impedir aprofundamento nas discussões.

Com efeito, em um processo real de planejamento não é razoável esperar que a convicção surja sem problemas ao longo do caminho; de fato, são frequentes os casos em que uma construção de convicção compartilhada entre os decisores é vítima de manipulações, distorções deliberadas, abusos de poder, julgamentos precipitados, estafa (física ou cognitiva), etc. Cabe aos planejadores atuar no sentido de minimizar as chances de que isso ocorra (FORESTER, 1989).

\section{O caráter dinâmico da formulação do problema}

Pelo fato de a estrutura do problema não estar clara no início do processo, os primeiros esforços frequentemente se concentram em tentar organizar a miríade de elementos iniciais oferecidos como contribuição à definição da situação decisional: opiniões genéricas, sugestões específicas, julgamentos de valor, fragmentos de dados ou estatísticas, memórias de experiências semelhantes, rancores e desconfianças guardados entre os atores envolvidos, modelos ou padrões considerados ideais, e assim por diante. Elementos de naturezas distintas são trazidos à tona para consideração e, se possível, compatibilização. Vamos chamá-los de Elementos Primários de Avaliação (EPA) ${ }^{6}$.

Essa fase é caracterizada por um grau de complexidade que demanda um alto esforço cognitivo para encontrar padrões, relações, similaridades e estrutura entre esses EPAs. Da mesma forma, esse esforço é direcionado também para identificar, dentre todos eles, quais são mais importantes e quais podem, sem riscos demasiados, ser descartados. Há uma busca por simplificação capaz de tornar o problema mais compatível com nossa capacidade cognitiva; todavia, essa busca também pode ter como consequência a supersimplificação do problema, ou a negligência com relação a aspectos relevantes.

Portanto, a etapa de estruturação do problema é um processo por meio do qual os participantes geram conhecimento sobre ele e, aos poucos, vão gerando um entendimento sobre o que é mais importante e o que é menos importante; quais são os pontos cruciais a serem decididos em cada etapa; quais são os objetivos e como eles se distribuem pelos diversos grupos de interesse; quais as alternativas existentes; e quais as principais consequências dessas alternativas. Esse entendimento é gradual independentemente do modelo normativo norteador utilizado.

A construção de clareza sobre qual é o problema, por conseguinte, não pode ser alcançada de imediato, e certamente não termina juntamente com a etapa de análise preliminar. Ao contrário, ela se estende por todo o processo e inclui a exploração e a criação de novas alternativas, as estimativas sobre suas consequências, os julgamentos dos decisores e demais envolvidos etc. Sob esse ponto de vista, alegar que há uma "etapa participativa" inicial e que a elaboração da proposta do plano possa ser feita exclusivamente pelos técnicos segundo os conhecimentos gerados nessa primeira etapa ${ }^{7}$ não faz sentido teórico nem prático.

\footnotetext{
6 Seguindo terminologia adotada em Ensslin, Montibeller e Noronha (2001).

7 Como aconteceu, por exemplo, em Florianópolis (RABELLO, 2012).
} 


\section{A dificuldade e a necessidade de estimar desdobramentos futuros}

Para poder decidir, as alternativas precisam ser avaliadas segundo os valores e objetivos dos decisores. Entretanto, não são as alternativas propriamente ditas que são avaliadas diretamente, e sim suas consequências. Mais precisamente, são as supostas consequências atribuídas às alternativas, consideradas em um determinado estágio de conhecimento do problema, que devem ser avaliadas. Alternativas não são boas ou más, adequadas ou inadequadas, satisfatórias ou insatisfatórias por si sós. Como, por definição, elas são meios para atingir os objetivos desejados, julgamentos sobre seu valor só podem ser feitos na medida em que seus possíveis efeitos são comparados com esses objetivos. Portanto, a implantação de uma nova via, por exemplo, não é boa ou má em si; seus efeitos, por outro lado, podem ser considerados bons ou maus, dependendo do contexto e das particularidades da situação e, obviamente, dos sistemas de valores que estão sendo usado para julgá-los, que são diferentes para diferentes grupos de interesses.

Entretanto, falar em "efeitos das alternativas" pode levar à falsa impressão de que esses efeitos são direta e facilmente depreendidos a partir delas, algo como uma consequência "natural" e livre de incertezas. Segundo essa visão, as ambiguidades e conflitos ficariam limitados apenas aos julgamentos desses efeitos, ou seja, apenas à atribuição de valores e preferências, que dependem de aspectos subjetivos. Todavia, a estimativa dos efeitos das alternativas envolve a previsão, que é um componente inerente ao planejamento, uma vez que este envolve a noção de que algumas ações (as alternativas adotadas) seriam capazes de melhorar o estado futuro das coisas, desde que sejam resultantes de um processo cuidadoso e deliberado de reflexão sobre o problema.

Isso é, obviamente, um ponto problemático do processo. Previsões sempre envolvem imprecisões, que por sua vez podem comprometer a acurácia das avaliações e, por consequência, a qualidade das decisões. Previsões tendem a ser mais acuradas quando feitas para horizontes curtos de tempo e em situações que envolvem número relativamente pequeno de variáveis. Quando as previsões buscam avançar por longos intervalos de tempo, precisam levar em conta múltiplos desdobramentos e interferências mútuas, bem como a maior incerteza associada a esses fatores. Entretanto, problemas urbanos são caracterizados exatamente por esses aspectos: repercussões em longos horizontes de tempo e um grande número de variáveis agindo simultaneamente, muitas das quais são desconhecidas ou de difícil descrição (RITTEL; WEBER, 1973), e cujas mútuas relações de influência são mapeadas apenas com muita dificuldade.

Previsões quanto às alternativas, portanto, envolvem feixes e cadeias de relações de causalidade segundo os quais as consequências previstas geram consequências, que, por sua vez, geram consequências, e assim por diante, em uma tentativa de prever um processo complexo de encadeamento de repercussões no sistema urbano. Esse processo se estende até que as consequências antevistas digam respeito a aspectos que façam sentido para os decisores e que sejam passíveis de comparação com seus objetivos, para, então, serem avaliadas.

Para realizar essas predições, tanto o conhecimento científico quanto o popular ou informal são utilizados. Presumivelmente, o primeiro seria mais adequado que o segundo, mas ele também possui limitações severas que não podem ser negligenciadas. Em primeiro lugar, teorias científicas são necessariamente representações limitadas e parciais da realidade. 0 grau máximo de simplificação aceitável nessa tradução do real para sua representação, todavia, não é claro nem definido $a$ priori em um contexto de planejamento, e por isso deve ser objeto de negociação e deliberação em cada situação específica (constituindo-se, portanto, em decisões de terceira ordem, processuais).

Além disso, um dos princípios mais fundamentais do conhecimento científico é sua pretensão de generalização, o que, entretanto, não evita a imposição de limites ao seu uso em situações específicas diferentes daquelas nas quais ele foi testado e corroborado. Certamente, algumas teorias podem ser consideradas mais robustas por terem resistido a testes em uma maior diversidade de contextos, mas mesmo nesses casos não é possível dizer com absoluta confiança que elas também seriam válidas para um problema decisional específico.

Por outro lado, a importância do conhecimento popular nos processos de planejamento vem adquirindo cada vez maior reconhecimento por parte dos 
técnicos em planejamento, acadêmicos, políticos e entidades da sociedade civil ${ }^{8}$. Com efeito, há informações vitais para as decisões em planejamento urbano que só podem ser obtidas por meio do conhecimento popular. Essas incluem os valores e desejos dos cidadãos, suas escalas de preferências, seus limites éticos e morais (que definem, por exemplo, as alternativas aceitáveis ou não), as idiossincrasias da população local, seus hábitos, experiências anteriores bem e malsucedidas etc.

\section{Meios, fins e conflitos de interesses}

Apesar de ser relativamente fácil obter consenso sobre os objetivos mais gerais, fazê-lo com os subobjetivos é uma tarefa consideravelmente mais complicada. Isso acontece porque as consequências intermediárias não produzem impactos apenas nos objetivos finais. Em sistemas complexos como são os urbanos, as teias de influências são extremamente ramificadas e, portanto, nunca são completamente incluídas nas considerações. Subobjetivos, portanto, possuem consequências que impactam em objetivos que não estão explícitos (mas nem por isso deixam de fazer parte do problema) e que são diferentes para diferentes grupos de interesses. Portanto, não importa apenas saber quais objetivos finais serão alcançados; é igualmente (ou mesmo mais) importante saber quais caminhos serão usados para chegar lá.

Nesses processos, objetivos finais podem estar tão distantes que os objetivos intermediários acabam sendo vistos pelos participantes como os reais objetivos a serem alcançados, aqueles que são viáveis e, portanto, pelos quais vale a pena lutar. Isso coloca sob nova luz a tradicional divisão entre meios e fins; essa definição é, na verdade, arbitrária, e pode ser enganosa, no sentido de que passa a impressão que a discussão real seria feita sobre os fins. Segundo essa visão, uma vez que esses estejam definidos, os debates sobre os meios deveriam possuir, supostamente, um caráter eminentemente técnico, limitando-se a prescrever os melhores caminhos definidos preferencialmente de modo científico para atingi-los de maneira mais efetiva. Entretanto, o entendimento dos meios como objetivos intermediários implica encarar as decisões sobre os meios a serem adotados como igualmente permeadas de valores e, portanto, sujeitas a interesses específicos e na maioria das vezes conflitantes.

Assim, mesmo que todos concordem, por exemplo, com o objetivo geral de promover o desenvolvimento socioeconômico do Município, a tendência é que cada grupo de interesses concentre-se na defesa daquele conjunto de alternativas que melhor atenda a seus objetivos intermediários, objetivos esses que, em grande parte dos casos, permanecem ocultos. Nesses casos, o que não é dito é tão ou mais importante do que o que é dito, assim como são reveladores os "erros" de raciocínio cometidos pelos atores - conforme a citação de Bertrand Russel (2008) que abre este artigo - quando discorrem sobre as possíveis e prováveis consequências das alternativas e quando optam por ressaltar apenas alguns aspectos, enquanto estrategicamente optam por não trazer outros à tona. As omissões, portanto, são especialmente reveladoras das reais intenções dos diversos grupos de interesses e merecem atenção especial no sentido de evitar distorções no processo.

\section{A necessidade de abrangência e exaustividade}

Pela conjunção da necessidade de convicção com a dificuldade em realizar previsões, é natural que aqueles envolvidos em uma decisão complexa busquem certificar-se de que estão levando em consideração todos os desdobramentos relevantes de uma ação ou alternativa. Se isso é possível ou não, é um outro aspecto; o fato é que decisores sentem a necessidade de minimizar suas incertezas, e a maneira mais direta e intuitiva de fazê-lo é ampliar a abrangência e a quantidade de informações sobre o problema.

Na etapa inicial de estruturação e detecção dos problemas que afligem a cidade, por exemplo, há a preocupação de que o diagnóstico ou a leitura abarquem todos os aspectos potencialmente importantes, de modo que não haja problemas que fiquem de fora das soluções apresentadas. Em processos participativos tal fenômeno é ampliado, uma vez

\footnotetext{
8 Ver, por exemplo: BRASIL, 2001; SANOFF, 2000; SOUZA, 2003.
} 
que a diversidade de perfis dos participantes tende a trazer diversidade equivalente de aspectos considerados relevantes. Traçar a linha que separa o que é essencial do que é secundário é particularmente difícil em processos participativos.

Uma vez identificados os problemas, as várias alternativas devem ser avaliadas segundo suas consequências, como descrito no item anterior, atividade também sujeita à necessidade de abrangência. Segundo o ponto de vista dos decisores, há sempre o risco de que alguma das consequências esteja sendo negligenciada, especialmente em ações com repercussões a longo prazo. Para poder haver convicção sobre a adequação ou não de uma alternativa, os decisores precisam ter segurança de que nenhuma consequência importante (e/ou potencialmente desastrosa) tenha sido deixada de fora. Entretanto, em um sistema complexo como são as cidades, é impossível obter segurança total quanto a isso. Há sempre o risco de que alguma coisa importante tenha sido deixada de fora, o que traz um desconforto psicológico aos decisores.

Esse desconforto não deve ser negligenciado: ele pode trazer sérios problemas ao andamento do processo, na medida em que cria conflitos entre os participantes sobre o momento de dar-se por satisfeito com o que está sendo considerado e seguir em frente. Em muitos casos, há participantes que se recusam a prosseguir enquanto não forem exploradas outras possibilidades, enquanto outros pressionam para passar para a próxima etapa. Obviamente, isso pode ser fruto de manipulações de ambas as partes (atrasando o processo para sabotá-lo ou pulando etapas para que determinados aspectos do problema não sejam levantados), mas muitas vezes são decorrência de preocupações legítimas. Saber se isso é o caso ou não, mais uma vez, é uma tarefa das decisões de terceira ordem, processuais, e portanto devem ser fruto de negociação entre os decisores.

Sobre esse aspecto, é importante destacar que há uma corrente na literatura da teoria do planejamento que critica fortemente o caráter abrangente do planejamento (LINDBLOM, 1959), não sem razão. Eles argumentam, em linhas gerais, que é impossível cobrir todos os aspectos importantes de um problema e que, por isso, é necessário adotar alternativas incrementais, caracterizadas por pequenas alterações sobre aquelas que já são executadas atualmente. Entretanto, ainda que essa diretriz normativa fosse considerada válida, é importante reconhecer que, psicologicamente, a necessidade de abrangência exerce forte influência nesses processos, em intensidade proporcional aos riscos envolvidos. Uma parte importante do processo de planejamento é justamente encontrar formas de definir, coletivamente, o equilíbrio entre o suficiente, o relevante e o possível, no que diz respeito à quantidade e qualidade do conhecimento já adquirido pelos decisores.

Processos que se arrastam por longos períodos de tempo tendem a esvaziar-se porque o custo cognitivo para fazer isso é alto. Tomar consciência do problema, explorar suas causas, tentar identificar as intrincadas linhas de causalidade existentes, separar o que é relevante do que é acessório, combinar os diversos pontos de vista em uma estrutura coerente, tudo isso são processos altamente exigentes do ponto de vista cognitivo. Se adicionamos a esse quadro a condição de grande parte dos participantes, voluntários que dedicam seu tempo e energia ao processo decisório após um dia inteiro de trabalho, vemos que esse custo não pode ser negligenciado e deve, portanto, ser incluído nas deliberações concernentes à abrangência das informações a serem coletadas e processadas.

\section{Considerações finais}

Vimos, pelo exposto, que a convicção em situações decisionais é algo frágil e que precisa de constante atenção e boa dose de conhecimento para ser construída sem que seja excessivamente distorcida. Essa é a principal função de um profissional encarregado de facilitar processos decisórios participativos. Certamente haverá, por parte dos atores, tentativas de sabotar a construção de convicção na direção de seus interesses, de forma consciente ou não, explícita ou disfarçadamente. Entretanto, o conhecimento sobre as condições sob as quais a convicção aparece (ou é prejudicada) pode auxiliar a reconhecer esses momentos e a neutralizar seus efeitos.

É importante também entender que a convicção não se limita a apenas um âmbito de decisão; ao contrário, seus efeitos transbordam de um nível de decisão para outro, influenciando-se mutuamente. Isso sugere que algumas modificações poderiam ser operadas sobre as legislações urbanísticas, em 
especial o plano diretor, para torná-las mais eficazes. Em primeiro lugar, os instrumentos adotados devem ser pensados e elaborados de forma a superar a noção determinística e a encaixar-se mais adequadamente em um processo de decisão (executiva) que possui, como vimos, certa autonomia em relação ao processo decisório que deu origem às diretrizes contidas no plano. Tanto os decisores quanto o contexto são outros e, portanto, as diretrizes de um plano diretor são apenas um dentre os vários aspectos que influenciam as decisões executivas. Obviamente, devem estar entre as mais importantes, mas certamente não serão as únicas.

Em vista disso, um mecanismo que poderia auxiliar na sua eficácia é a preocupação prévia com a necessidade futura de geração de convicção nos executores, ou seja, a busca por meios para gerar (ou reforçar) a convicção de que diretrizes presentes no plano são adequadas e devem ser seguidas. Decisões de segunda e terceira ordens, portanto, podem e devem ser pensadas de modo a maximizar a convicção em decisões de primeira ordem. Nesse sentido, os planos diretores podem contribuir se tiverem a preocupação de explicitar as justificativas para as decisões tomadas ao longo do seu processo de elaboração. Contudo, o formato de lei é desfavorável à inclusão de justificativas no corpo do texto ${ }^{9}$, razão pela qual tais elementos acabam constando apenas das exposições de motivos que acompanham os projetos de lei no momento de sua discussão e aprovação na Câmara de Vereadores. Ainda assim, é comum encontrarmos exposições de motivos breves e genéricas, limitando-se a ressaltar a importância do plano diretor como um todo e apenas muito raramente abordando os porquês das diretrizes, estratégias e instrumentos adotados. Opções interessantes são as leis comentadas, das quais um raro exemplo, no que concerne aos Planos Diretores, é a de Porto Alegre ${ }^{10}$, e cartilhas explicativas como a de São Paulo (SP) (BONDUKI et al., 2004).

Outra forma de aumentar a convicção sobre a adequação do plano no momento das decisões executivas é envidar esforços para que as decisões processuais sejam justas, democráticas e transparentes, e garantir que os elementos necessários para comprovar essas qualidades estejam documentados na versão a ser divulgada. A inclusão de uma ampla gama de participantes e interesses diversos, assim como a justiça processual, está associada a uma não arbitrariedade das decisões. Executores tendem a dar maior peso às decisões tomadas em conjunto, por meio de processos transparentes e reconhecidos, do que àquelas tomadas em gabinete por um grupo restrito de pessoas. Além disso, a documentação do processo permite maior eficácia na pressão a ser exercida sobre os responsáveis pela execução, tanto no que diz respeito às vias jurídicas quanto à opinião pública.

Há, portanto, a necessidade de considerar o processo de planejamento urbano sob uma outra lógica: de uma noção ligada majoritariamente a simulações, modelos, estimativas, mapas, dados numéricos e estudos substantivos em geral, é forçoso incorporar os aspectos processuais como igualmente importantes e, neles, considerar as limitações cognitivas e seus impactos nos processos decisórios. Apenas reconhecendo a real complexidade envolvida, poderemos avançar na direção de cidades melhores e mais justas.

\section{Referências}

ALFASI, N.; PORTUGALI, J. Planning just-in-time versus planning just-in-case. Cities, v. 21, n. 1, p. 29-39, 2004.

ARIELY, D. Predictably irrational: the hidden forces that shape our decisions. New York: Harper Collins, 2008.

BANA E COSTA, C. A. As três convicções fundamentais na prática do apoio à decisão. Revista Pesquisa Operacional, v. 13, n. 1, 1993.

BARON, J. Thinking and deciding. New York: Cambridge University Press, 2008.

BONDUKI, N. et al. São Paulo - Plano Diretor Estratégico: cartilha de formação. 3.ed. São Paulo: Gabinete do Vereador Nabil Bonduki, 2004.

\footnotetext{
9 A Lei Complementar n. 96/1998, por exemplo, que dispõe sobre a elaboração de leis, cita a necessidade de "ensejar perfeita compreensão do objetivo da lei e a permitir que seu texto evidencie com clareza o conteúdo e o alcance que o legislador pretende dar à norma" (Art. 11-II-a), sem fazer menção à necessidade de justificativas para os dispositivos.

${ }^{10}$ Disponível em: <http://www.portoalegre.rs.gov.br/planeja/spm/default.htm>. Acesso em: 18 out. 2013.
} 
BRASIL. Estatuto da Cidade: guia para implementação pelos municípios e cidadãos. Brasília: Câmara dos Deputados; Coordenação de Publicações, 2001.

BRYSON, J. Strategic planning for public and nonprofit organizations: a guide to strengthening and sustaining organizational achievement. San Francisco: Jossey-Bass, 2004.

CLÍMACO, J. A critical refection on optimal decision. European Journal of Operational Research, v. 153, n. 2, p. 506-516, 2004.

DAVIDOFF, P.; REINER, T. A. A choice theory of planning. In: FALUDI, A. (Org.). A reader in planning theory. Oxford: Pergamon Press, 1973. p. 11-44.

EDEN, C.; JONES, S. Messing about in problems: an informal structured approach to their identification and management. Oxford: Pergamon Press, 1983.

ENSSLIN, L.; MONTIBELLER NETO, G.; NORONHA, S. M. Apoio à decisão: metodologias para estruturação de problemas e avaliação multicritério de alternativas. Florianópolis: Insular, 2001.

FALUDI, A. A reader in planning theory. Oxford: Pergamon Press, 1973.

FALUDI, A. A decision-centred view of environmental planning. Oxford: Pergamon Press, 1987.

FORESTER, J. Planning in the face of power. Berkeley: University of California Press, 1989.

FRIEND, J.; HICKLING, A. Planning under pressure. Oxford: Elsevier, 2005

FURNHAM, A.; BOO, H. C. A literature review of the anchoring effect. The Journal of Socio-Economics, v. 40, n. 1, p. 35-42, 2011.

INNES, J. Planning through consensus building: a new view of the comprehensive planning ideal. Journal of the American Planning Association, v. 62, n. 4, p. 460-472, 1996.

KAHNEMANN, D. Thinking, fast and slow. New York: Farrar, Straus and Giroux, 2011.
LINDBLOM, C. E. The Science of "Muddling Through". Public Administration Review, v. 19, n. 2, p. 79-88, 1959.

McLOUGHLIN, J. B. Urban \& regional planning: a systems approach. London: Faber and Faber, 1969.

MINTZBERG, H.; RAISINGHANI, D.; THÉORÊT, A. The Structure of "Unstructured" Decision Processes. Administrative Science Quarterly, v. 21, n. 2, p. 246-275, 1976.

RABELLO, T. Aspecto comunicativo do processo de elaboração de planos diretores: lições a partir da experiência de Florianópolis - SC. 2012. Dissertação (Mestrado em Arquitetura e Urbanismo) - Universidade Federal de Santa Catarina, Florianópolis, 2012.

RITTEL, H.; WEBBER, M. Dilemmas in a general theory of planning. Policy Sciences, v. 4, n. 2, p. 155-169, 1973.

ROY, B. Decision science or decision-aid science. European Journal of Operational Research, v. 66, n. 2, p. 184-203, 1993.

ROY, B. Multicriteria methodology for decision aiding. Dordrecht: Kluwer Academic Publishers, 1996.

RUSSEL, B. Ensaios céticos. Porto Alegre: LP\&M Editores, 2008.

SANOFF, H. Community participation methods in design and planning. New York: John Wiley \& Sons, 2000.

SANTOS Jr., O.; MONTANDON, D. (Org.). Os Planos Diretores Municipais Pós-Estatuto da Cidade: balanço crítico e perspectivas. Rio de Janeiro: Letra Capital; Observatório das Cidades, 2011.

SIMON, H. A behavioral model of rational choice. The Quarterly Journal of Economics, v. 69, n. 1, p. 99-118, 1955.

SIMON, H. The structure of ill-structured problems. Artificial Intelligence, v. 4, p. 181-201, 1973.

SIMON, H. A. The sciences of the artificial. Cambridge: MIT Press, 1981. 
SOUZA, M. L. Mudar a cidade: uma introdução crítica ao planejamento e à gestão urbanos. Rio de Janeiro: Bertrand Brasil, 2003.

TVERSKY, A.; KAHNEMAN, D. Judgment under uncertainty: heuristics and biases. Science, v. 185, n. 4157, p. 1124-1131, 1974.
VAINER, C. B. Pátria, empresa e mercadoria: notas sobre a estratégia discursiva do Planejamento Estratégico Urbano. In: ARANTES, O. B. F.; MARICATO, E.; VAINER, C. (Org.). A cidade do pensamento único: desmanchando consensos. Petrópolis: Vozes, 2002.

Recebido: 05/02/2013

Received: 02/05/2013

Aprovado: 08/06/2013

Approved: 06/08/2013 